University of South Florida

DIGITAL COMMONS

@ UNIVERSITY OF SOUTH FLORIDA
Digital Commons @ University of

South Florida

$7-1-2006$

\title{
Evaluation of Automated Vehicle Technology for Transit
}

CUTR

Follow this and additional works at: https://digitalcommons.usf.edu/cutr_nctr

\section{Recommended Citation}

"Evaluation of Automated Vehicle Technology for Transit," National Center for Transit Research (NCTR) Report No. CUTR-NCTR-RR-2014-04, Center for Urban Transportation Research, University of South Florida, 2006.

DOI: https://doi.org/10.5038/CUTR-NCTR-RR-2014-04

Available at: https://scholarcommons.usf.edu/cutr_nctr/80

This Technical Report is brought to you for free and open access by the National Center for Transit Research (NCTR) Archive (2000-2020) at Digital Commons @ University of South Florida. It has been accepted for inclusion in Research Reports by an authorized administrator of Digital Commons @ University of South Florida. For more information, please contact digitalcommons@usf.edu. 


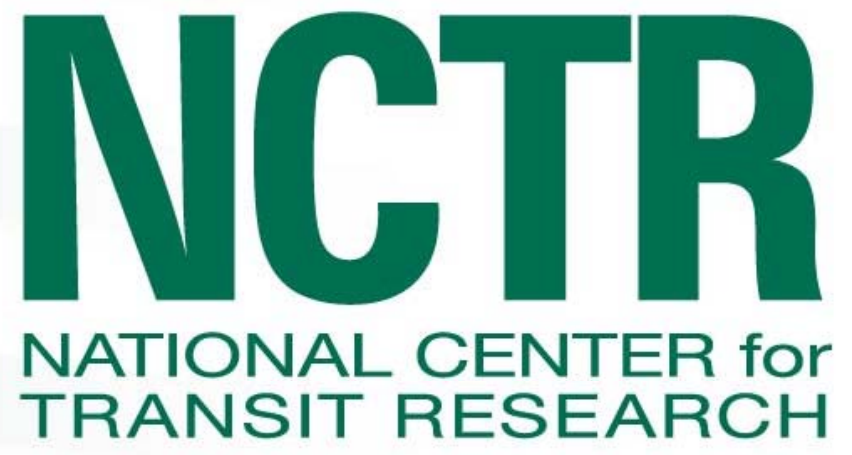

Evaluation of Automated Vehicle Technology for Transit BDV26 977-07

January 2015

FINAL REPORT

PREPARED FOR

Florida Department of Transportation

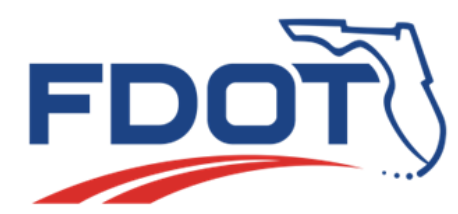




\section{Disclaimer}

The opinions, findings, and conclusions expressed in this publication are those of the authors and not necessarily those of the State of Florida Department of Transportation. 


\section{Metric Conversion}

\begin{tabular}{|c|c|c|c|c|}
\hline SYMBOL & WHEN YOU KNOW & MULTIPLY BY & TO FIND & SYMBOL \\
\hline \multicolumn{5}{|c|}{ LENGTH } \\
\hline in & inches & 25.4 & millimeters & $\mathrm{mm}$ \\
\hline $\mathrm{ft}$ & feet & 0.305 & meters & $\mathrm{m}$ \\
\hline yd & yards & 0.914 & meters & $\mathrm{m}$ \\
\hline mi & miles & 1.61 & kilometers & $\mathrm{km}$ \\
\hline \multicolumn{5}{|c|}{ VOLUME } \\
\hline fl oz & fluid ounces & 29.57 & milliliters & $\mathrm{mL}$ \\
\hline gal & gallons & 3.785 & liters & $\mathrm{L}$ \\
\hline $\mathrm{ft}^{3}$ & cubic feet & 0.028 & cubic meters & $\mathrm{m}^{3}$ \\
\hline$y d^{3}$ & cubic yards & 0.765 & cubic meters & $\mathrm{m}^{3}$ \\
\hline \multicolumn{5}{|c|}{ Note: volumes greater than $1000 \mathrm{~L}$ shall be shown in $\mathrm{m}^{3}$} \\
\hline \multicolumn{5}{|c|}{ MASS } \\
\hline oz & ounces & 28.35 & grams & g \\
\hline lb & pounds & 0.454 & kilograms & $\mathrm{kg}$ \\
\hline $\mathbf{T}$ & short tons $(2000 \mathrm{lb})$ & 0.907 & $\begin{array}{c}\text { megagrams } \\
\text { (or metric } \\
\text { ton) }\end{array}$ & $\begin{array}{l}\text { Mg (or } \\
\text { "t") }\end{array}$ \\
\hline \multicolumn{5}{|c|}{ TEMPERATURE (exact degrees) } \\
\hline${ }^{\circ} \mathbf{F}$ & Fahrenheit & $\begin{array}{c}5(F-32) / 9 \text { or } \\
(F-32) / 1.8\end{array}$ & Celsius & ${ }^{\circ} \mathrm{C}$ \\
\hline
\end{tabular}


Technical Report Documentation

\begin{tabular}{|c|c|c|c|c|}
\hline $\begin{array}{l}\text { 1. Report No. } \\
\text { n/a }\end{array}$ & \multicolumn{2}{|c|}{ 2. Government Accession No. } & \multicolumn{2}{|l|}{ 3. Recipient's Catalog No. } \\
\hline \multirow{2}{*}{\multicolumn{3}{|c|}{$\begin{array}{l}\text { 4. Title and Subtitle } \\
\text { Evaluation of Automated Vehicle Technology in Transit }\end{array}$}} & \multicolumn{2}{|l|}{ 5. Report Date } \\
\hline & & & \multicolumn{2}{|c|}{ 6. Performing Organization Code } \\
\hline \multicolumn{3}{|l|}{$\begin{array}{l}\text { 7. Author(s) } \\
\text { Brian Pessaro, AICP }\end{array}$} & \multicolumn{2}{|c|}{ 8. Performing Organization Report No. } \\
\hline \multirow{2}{*}{\multicolumn{3}{|c|}{$\begin{array}{l}\text { 9. Performing Organization Name and Address } \\
\text { National Center for Transit Research } \\
\text { Center for Urban Transportation Research (CUTR) } \\
\text { University of South Florida } \\
\text { 4202 E. Fowler Ave., CUT } 100 \\
\text { Tampa, FL 33620-5375 }\end{array}$}} & \multicolumn{2}{|l|}{ 10. Work Unit No. (TRAIS) } \\
\hline & & & \multicolumn{2}{|l|}{$\begin{array}{l}11 . \text { Contract or Grant No. } \\
\text { BDV26 977-02 }\end{array}$} \\
\hline \multirow{2}{*}{\multicolumn{3}{|c|}{$\begin{array}{l}\text { 12. Sponsoring Agency Name and Address } \\
\text { Florida Department of Transportation } \\
\text { Research Center } \\
\text { 605 Suwannee Street, MS } 30 \\
\text { Tallahassee, FL 32399-0450 }\end{array}$}} & \multicolumn{2}{|c|}{\begin{tabular}{|l|} 
13. Type of Report and Period Covered \\
Final Report, January 2015
\end{tabular}} \\
\hline & & & \multicolumn{2}{|c|}{ 14. Sponsoring Agency Code } \\
\hline \multicolumn{5}{|l|}{ 15. Supplementary Notes } \\
\hline \multicolumn{5}{|c|}{$\begin{array}{l}\text { 16. Abstract } \\
\text { The purpose of this report is to provide an overview of the state of automated vehicle (AV) technology } \\
\text { in transit. The Florida Department of Transportation (FDOT) wishes to know what AV technology is } \\
\text { currently available that could be used in transit with an eye towards possible demonstration projects. It } \\
\text { finds that the operational use of AV technology by transit in the U.S. has been limited to a few } \\
\text { prototypes. With one exception, there are no immediate plans by bus manufacturers to add AV } \\
\text { technology to their vehicles. The exception was Volvo/Nova Bus. They are considering adding a } \\
\text { bicycle/pedestrian warning system to their buses. It appears that for the moment any new } \\
\text { demonstrations of AV technology in transit would involve significant engineering work and retrofitting } \\
\text { of buses. }\end{array}$} \\
\hline \multicolumn{2}{|c|}{$\begin{array}{l}\text { 17. Key Words: Managed Lanes, transit, carpooling, tolls } \\
\text { automated vehicles, transit, connected vehicles }\end{array}$} & \multicolumn{3}{|c|}{ 18. Distribution Statement } \\
\hline $\begin{array}{l}\text { 19. Security Classif. (of this report) } \\
\text { Unclassified }\end{array}$ & $\begin{array}{r}\text { 20. Security } \mathrm{Cl} \\
\mathrm{Un}\end{array}$ & $\begin{array}{l}\text { (of this page) } \\
\text { ified }\end{array}$ & \begin{tabular}{|c|} 
21. No. of Pages \\
13
\end{tabular} & 22. Price \\
\hline
\end{tabular}




\section{Table of Contents}

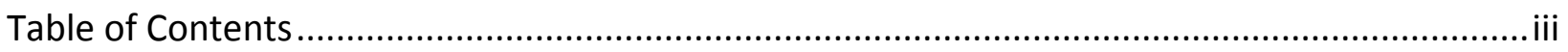

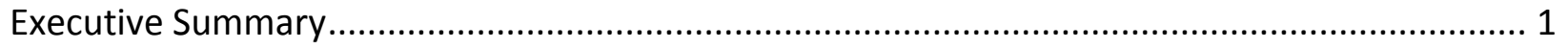

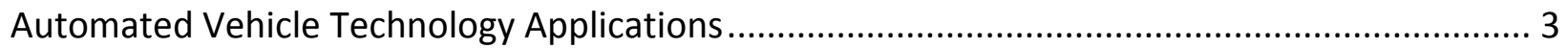

Minnesota Valley Transit Authority Driver Assist System ...................................................... 3

Lane Transit District Precision Docking through Magnetic Guidance ....................................... 4

San Diego Association of Governments Bus on Shoulders System (BOSS) ............................... 5

USDOT Connected Vehicle Safety Pilot Model Deployment .................................................. 6

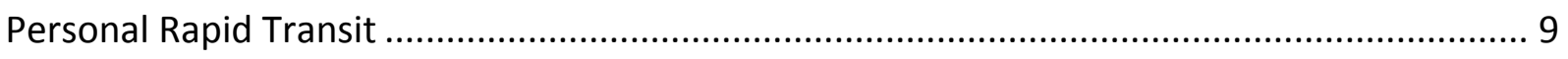

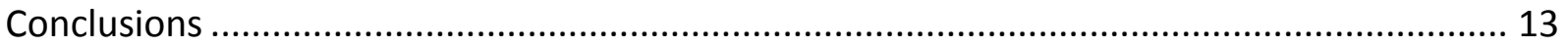




\section{List of Figures}

Figure 1 View through MVTA Head-Up Display .................................................................... 4

Figure 2 System Components of Lane Transit District Magnetic Guidance System..................... 5

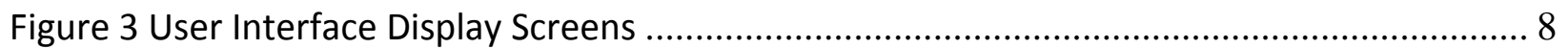

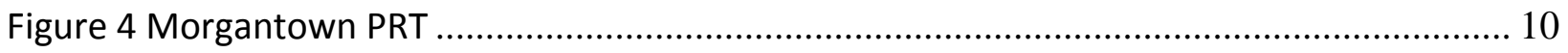

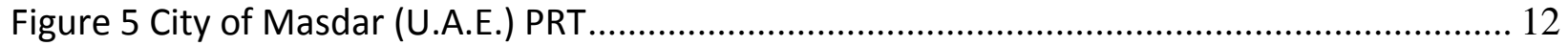

Figure 6 London Heathrow Airport PRT .......................................................................... 12

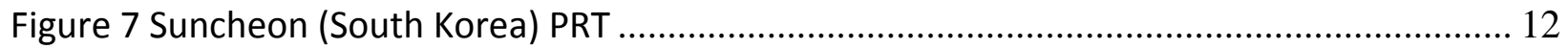

\section{List of Tables}

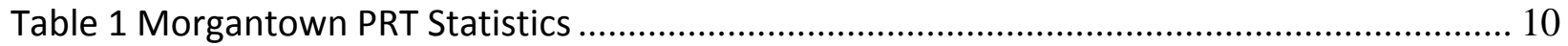




\section{Executive Summary}

The purpose of this report is to provide an overview of the state of automated vehicle (AV) technology in transit. The Florida Department of Transportation (FDOT) wishes to know what AV technology is currently available that could be used in transit with an eye towards possible demonstration projects. Many car manufacturers already offer limited AV technology in some of their models. For example, Acura, Lexus, Audi, Mercedes, Volkswagen, BMW, and Infiniti all currently offer lane keep assist, advanced collision warning, and adaptive cruise control. However, it remains to be seen what the transit industry will do in regards to AV technology. The FDOT has assembled a stakeholder working group to address the opportunities and challenges that automated vehicles may hold for roadways in Florida. In December 2014, the FDOT will host an Automated Vehicles Summit in Orlando. On the transit front, the FDOT is currently testing collision avoidance technology manufactured by Mobileye on transit vehicles in FDOT District 7.

As part of the research effort for this paper, the Center for Urban Transportation Research (CUTR) reached out to several U.S. bus manufactures to ask whether they currently offer or plan to offer AV technology in any of their model buses. The bus manufacturers contacted included New Flyer/NAB ${ }^{1}$, Gillig, El Dorado National, Nova Bus $/$ Volvo ${ }^{2}$, and Proterra. With the exception of Nova Bus/Volvo, none of the bus manufacturers contacted have plans to add AV technology. The one exception was Nova Bus/Volvo. However, the only system that they are considering adding is a pedestrian/bicyclist warning system. It does not involve any automation of vehicle operation.

CUTR reached out to its contacts in Europe to see if there have been any new developments in AV technology there for public transit. The International Association of Public Transport (UITP) has been involved in two projects related to updating public transit vehicles in Europe: the European Bus System of the Future project and the follow-on 3iBS project. However, in both cases, the emphasis has been on improving vehicle aesthetics rather than adding AV technology. There are no immediate plans to make AV technology a priority for transit in Europe.

To date, there are only two operational uses of transit-related AV technology in the U.S. Both are prototypes developed by universities under Federal Transit Administration (FTA) grants. In Apple Valley, Minnesota, a suburb south of Minneapolis, the Minnesota Valley Transit Authority contracted with the University of Minnesota to develop a GPS-based driver assist system to improve safety during bus shoulder operations. In Eugene, Oregon, Lane Transit District contracted with the Partners for Advanced Transit and Highways (PATH) at UC Berkeley. PATH developed a magnetic guidance system that is used for precision docking by the EmX bus rapid transit (BRT) system at three stations. More information on both of these projects is included in the report.

\footnotetext{
${ }^{1}$ North American Bus Industries (NABI) was acquired by New Flyer in June 2013.

${ }^{2}$ NOVA Bus is a subsidiary of Volvo.
} 
The only AV project that CUTR could find involving a commercial manufacturer was a project sponsored the San Diego Association of Governments (SANDAG). However, it did not come to fruition. SANDAG had contracted with TRW Automotive to outfit a number of New Flyer buses with adaptive cruise control and lane departure warning. The technology was to be used for a new service called the BOSS (Bus on Shoulder System) that was to operate on I-805. Although the project fell through, according to staff from SANDAG, it was not through any fault on the part of TRW. Representatives from TRW stated to CUTR that it would be possible to undertake a similar demonstration project with the FDOT. However, TRW also stated that their technology is "not fully off-the-shelf" (their words), and a demo project would require "a significant package of application and safety engineering work." More information on the TRW technology is provided in the report.

There are four operational Personal Rapid Transit (PRT) systems in the world - the Morgantown PRT in West Virginia, the City of Masdar PRT in the United Arab Emirates, the London Heathrow Airport PRT, and the Suncheon Bay PRT in South Korea. Sometimes referred to as "podcars", PRT is a system of driverless taxicabs that take passengers to their destination along dedicated guideways without intermediate stops. Because the latter three PRT systems have been private ventures, it has been difficult to track down construction costs. The only information that could be found was a news article on the London Heathrow PRT that estimated the capital costs for the 2.4 mile, 21 podcar, 3 station system at $£ 30$ million ( $\$ 51$ million).

Finally, this report includes a summary of what has been learned to date from the transit subcomponent of the USDOT's Connected Vehicle Safety Pilot Model Deployment in Ann Arbor Michigan. Although CV technology is separate from AV technology, it nevertheless holds the promise of improving safety by enhancing driver awareness. The Transit Safety Retrofit Project involved retrofitting three test buses with five safety applications. They included Forward Collision Warning, Emergency Electronic Brake Lights, Curve Speed Warning, Pedestrian in Signalized Crosswalk Warning, and Vehicle Turning Right in Front of Bus Warning. 


\section{Automated Vehicle Technology Applications}

\section{Minnesota Valley Transit Authority Driver Assist System}

In 2010, the Minnesota Valley Transit Authority (MVTA) began using a GPS-based driver assist system to improve the safety and frequency of bus shoulder operations. In Minnesota, buses are allowed by state law to use highway shoulder lanes when speeds in the general purpose lanes drop below 35 miles per hour. MVTA was interested in developing a tool that would encourage the bus drivers to use the shoulder lanes during inclement weather when the shoulder boundaries are obscured by snow.

The Intelligent Vehicles Lab at the University of Minnesota developed and integrated the driver assist system. It uses a combination of GPS and highly accurate digital maps to track the exact position of the bus within the shoulder lane. In addition, lidar is used to warn the driver of vehicles and other obstacles to the side of the bus. Lidar, which stands for Light Detection and Ranging, uses light in the form of a pulsed laser to measure ranges.

The bus driver receives three types of feedback: visual, tactile, and haptic. Visual feedback is provided by a head-up display (HUD) and a virtual mirror. The HUD digitally displays the shoulder boundaries and alerts the bus driver to any vehicles getting too close. A view through the HUD is shown in Figure 1. The virtual mirror shows vehicles in the adjacent lane and is meant to help the drivers merge from the shoulder lane back into the general purpose lanes. Tactile feedback is provided by vibrators located in both sides of the seat bottom cushion. They create the sensation of a virtual rumble strip when the bus drifts too far left or right from the center of the shoulder. The final form of feedback is the haptic steering. This is provided through a motor attached to the steering column that applies torque when the bus drifts too far left or right in the shoulder.

The total project cost was $\$ 5.3$ million to outfit ten buses with the technology and to create a driver assist system simulator (essentially a mock-up of a MVTA bus similar to a flight simulator) for training. CUTR evaluated the driver assist system for the Federal Transit Administration (FTA) in 2011. The evaluation was entitled "Cedar Avenue Driver Assist Evaluation Report" and is available online via the FTA website. ${ }^{3}$ The evaluation confirmed that the system improved bus operations and reduced driver stress. When the system was activated, the bus drivers stayed in the shoulders 4.3 percent longer, drove 3.5 miles per hour faster, and reduced their side to side movement by 4.7 inches. The developer of the Minnesota system, Dr. Craig Shankwitz, has since left the University of Minnesota and works for MTS Systems Corporation. The website for MTS is www.mts.com, and the contact information for Dr. Shankwitz is Craig.Shankwitz@mts.com.

\footnotetext{
${ }^{3}$ http://www.fta.dot.gov/documents/FTA_Report_No._0010.pdf
} 


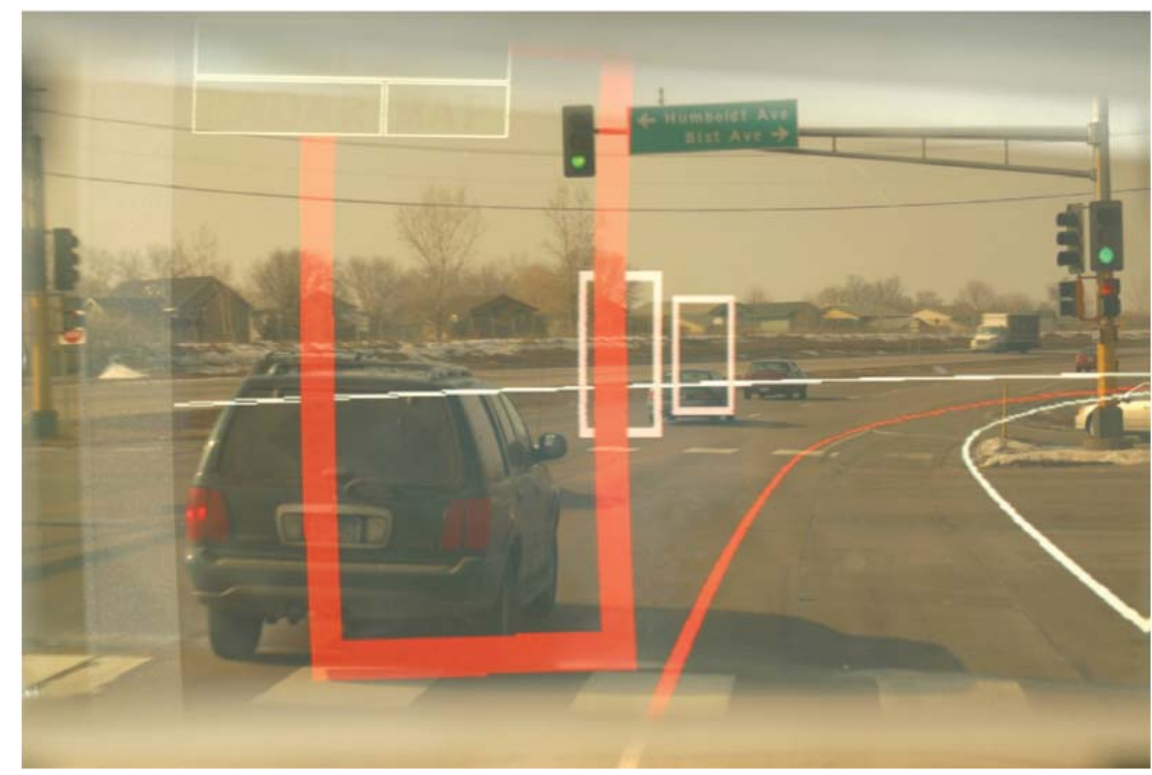

Figure 1 View through MVTA Head-Up Display

\section{Lane Transit District Precision Docking through Magnetic Guidance}

Lane Transit District (LTD) in Eugene, Oregon has partnered with the California Department of Transportation (Caltrans) and the Partners for Advanced Transit and Highways Program at UC Berkeley in a FTA demonstration of magnetic marker sensing technology. LTD is using the technology to facilitate precision docking of their EmX Bus Rapid Transit (BRT) at three stations along a 1.5 mile segment of the Franklin Corridor. Single rare earth magnets were installed in the concrete running way spaced 3 to 4.25 feet apart to create a magnetic track. One articulated New Flyer bus was equipped with two magnetometer sensor bars, one in front of the front wheels and the other under the middle door. The magnetometers measure the lateral position of the bus in relation to the magnetic track. A lateral control computer then calculates the needed steering adjustment and sends a command to a steering actuator which turns the steering wheel. A figure of the system components is shown in Figure 2. The preliminary results were reported to the Federal Transit Administration in February 2014. ${ }^{4}$ The target horizontal gap between the bus and the platform with the technology enabled was $4 \mathrm{~cm}$. The actual gap, based on twelve round-trip automated runs was $+2 \mathrm{~cm}$ for both the very sharp (25-35 meter radius) and the relatively mild ( 100 meter radius) docking curves. CUTR will be conducting a more thorough evaluation with a larger dataset throughout 2014 and early 2015.

The developer of the magnetic system used by Lane Transit District is the Partners for Advanced Transit and Highways (PATH) Program at UC Berkeley. The contact person is Han-Shue Tan at hstan@path.berkeley.edu.

\footnotetext{
${ }^{4}$ Pilot Program to Demonstrate the Benefits of Vehicle-Assist and Automation (VAA) Applications for Full-Size Public Transit Buses: System Performance and Evaluation: Preliminary Results, February 2014.
} 


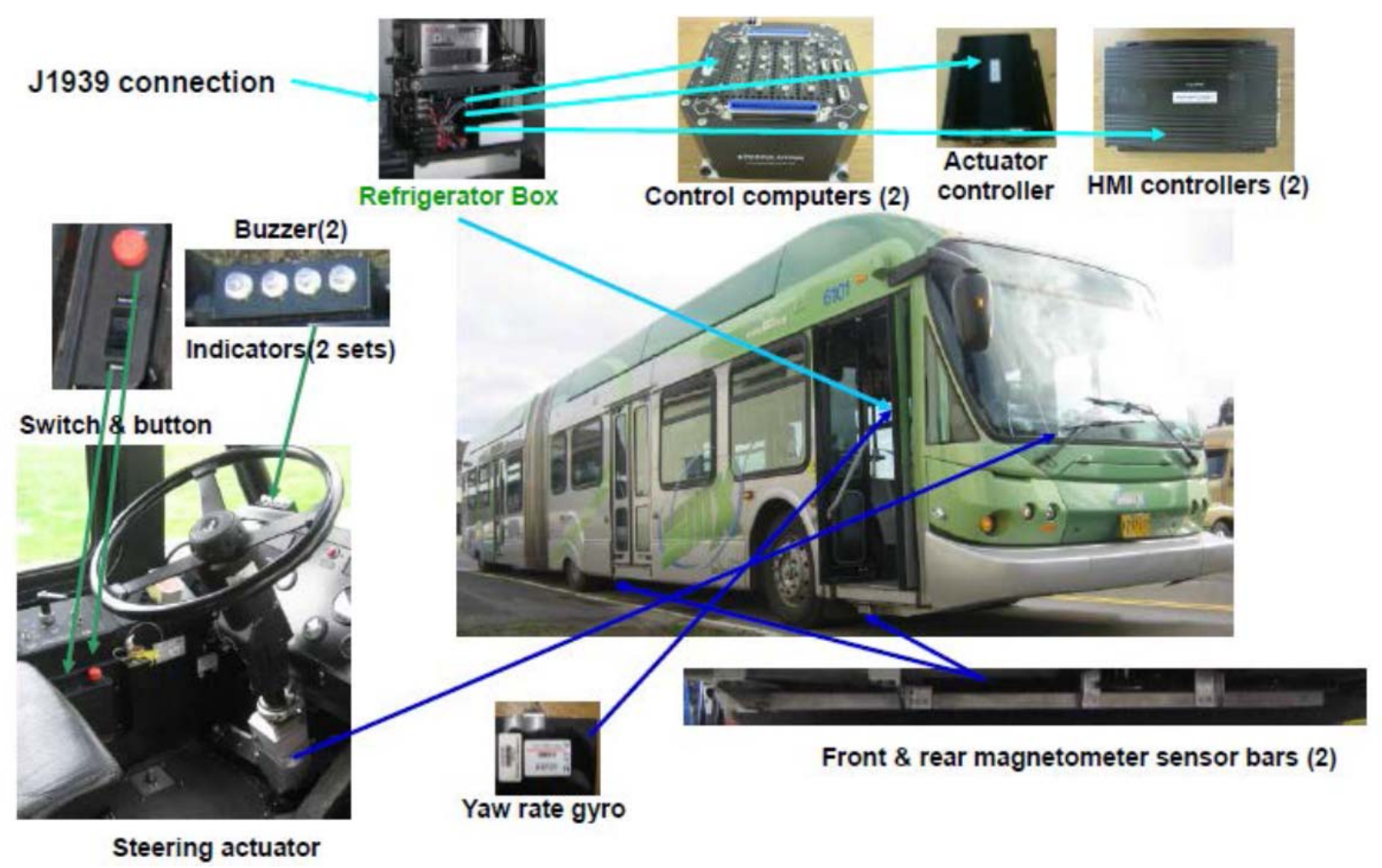

Figure 2 System Components of Lane Transit District Magnetic Guidance System

\section{San Diego Association of Governments Bus on Shoulders System (BOSS)}

In 2008, the San Diego Association of Governments (SANDAG) issued a request for proposals for a $\$ 4.7$ million vehicle assist and automation demonstration. Although the project never came to fruition, it is included in the report since the technology is still available from the vendor, TRW. SANDAG referred to this project as the Bus on Shoulders System or BOSS. The project was to consist of ten buses being outfitted with adaptive cruise control, lane keep assist technology, as well as advanced warning systems for forward collision, lane departure, and obstacle detection. The technology was to be used on a new peak-period express service operating in an 11-foot limited access lane in the median of Interstate 805. SANDAG and Caltrans were planning to refurbish the interior shoulder lane for use as a bus lane. The demonstration was meant to showcase how vehicle assist and automation technology could help bus drivers operate in a narrow lane environment. Because of changes in Caltrans' construction schedule on I-805, the project did not become operational.

SANDAG had selected TRW as the technology vendor for the demonstration project. TRW Conekt, which is one of TRW's operational divisions, was to take the lead. SANDAG was purchasing the buses through a separate contract with New Flyer. The plan was for TRW Conekt to work with New Flyer and integrate their technology into the buses. Both the adaptive cruise control and forward collision warning system were to be radar based while the lane keep assist 
technology was to be camera based. Vehicle detection on the side of the bus was to be handled through lidar.

TRW still offers the technology should FDOT wish to pursue a similar demonstration project. However, TRW Conekt staff acknowledged that there would be a significant amount of engineering work required. TRW Conekt is located in Solihull, England. Their website advertises that as part of TRW they are able "to offer the advantages of mass produced systems to niche and low volume applications." The TRW Conekt website is http://www.conekt.co.uk/. Their contact email is conekt-enquiries@trw.com.

\section{USDOT Connected Vehicle Safety Pilot Model Deployment}

In April 2012, the United States Department of Transportation began the Connected Vehicle Safety Pilot Model Deployment. This project, conducted in Ann Arbor, Michigan, involved approximately 3,000 cars, trucks, and transit vehicles equipped with wireless communications devices to improve safety. ${ }^{5}$ The purpose of the program was to test the efficacy of crash warning and avoidance systems based on vehicle-to-vehicle (V2V) and vehicle to infrastructure (V2I) technologies communicating with dedicated short-range communications (DSRC).

The Transit Safety Retrofit Project was a subcomponent of the model deployment. It involved retrofitting three University of Michigan buses with five V2V and V2I safety applications. The visual and aural alerts for these applications were provided through an Android tablet mounted inside the bus. The descriptions of the five safety applications are provided in the paragraphs below.

The Forward Collision Warning (FCW) is a V2V application. FCW is intended to warn the bus driver in case of an impending rear-end collision with an equipped remote vehicle ahead in traffic in the same lane and direction of travel. FCW is intended to help drivers in avoiding or mitigating rear-end vehicle collisions in the forward path of travel.

The Emergency Electronic Brake Lights (EEBL) is a V2V application. EEBL decodes broadcasts of a self-generated emergency brake event from surrounding equipped remote vehicles. Upon receiving such event information, the EEBL application determines the relevance of the event and provides a warning to the bus driver if appropriate. This application is particularly useful when the driver's line of sight is obstructed by other vehicles or bad weather conditions (e.g., fog, heavy rain).

The Curve Speed Warning (CSW) is a V2I application. CSW aids drivers in negotiating curves at appropriate speeds. This application uses information communicated from a roadside unit (RSU) located ahead of approaching curves. The communicated information from the RSU

\footnotetext{
${ }^{5}$ http://www.metro-magazine.com/article/story/2014/05/connected-vehicle-testing-aims-to-bolster-bussafety.aspx
} 
would include curve location, curve speed limits, curvature, bank, and road surface condition. The device would determine, using other vehicle information, such as speed and acceleration whether the driver needs to be alerted. This application requires the ability to receive a message from the roadside equipment. The CSW is triggered when the bus travels $10 \mathrm{mph}$ over the posted speed limit for the subject curve.

The Pedestrian in Signalized Crosswalk Warning (PSCW) is a V2I application. PSCW warns a bus driver if pedestrians are in the intended path of the bus when making a right or left turn. This application incorporates two methods of detecting pedestrians - activation of the crosswalk button by a pedestrian and a microwave motion sensor that detects the presence of pedestrians in the crosswalk. The application provides two levels of alerts to the driver-an informational/cautionary indicator if the crosswalk button is activated and an imminent warning if a pedestrian is actually detected in the crosswalk.

The Vehicle Turning Right in Front of Bus Warning (VTRW) is a V2V application. VTRW warns a bus driver of the presence of vehicles attempting to go around the bus to make a right turn as the bus departs from a bus stop. The application includes two levels of alerts to the driver-an informational/cautionary indicator if an equipped vehicle has moved from behind to beside the bus and an imminent warning if the equipped vehicle shows intent to turn in front of the bus.

Image captures of the visual alerts that appear on the bus driver's Android tablet are shown in Figure 3. These five applications were deployed from February 2013 to September 2013 (8 months). During that time, 23,211 events were captured of which 1,995 were Warnings and 1,720 were Cautions (Informs). After the initial 8-month deployment, some limited refinements were made to the software and hardware. The applications were then re-redeployed for four additional weeks in February and March 2014. During that time, 4,730 events were captured, of which 294 were Warnings and 262 were Cautions (Informs). 


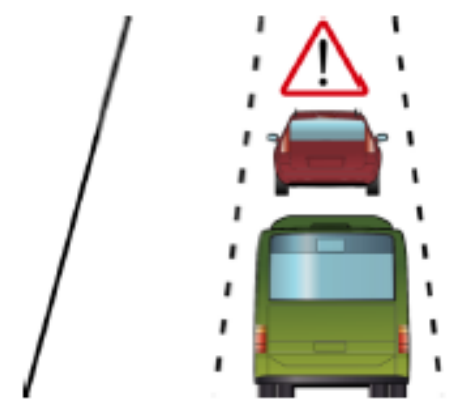

FCW Warning Display Screen

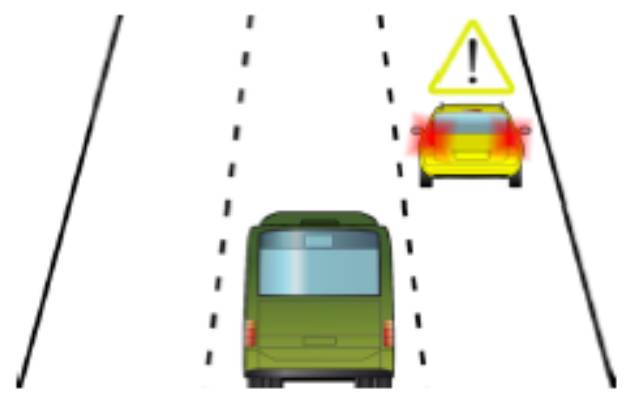

EEBL Inform Display Screen

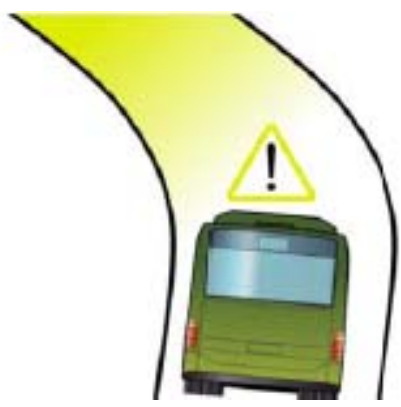

CSW Inform Display Screen

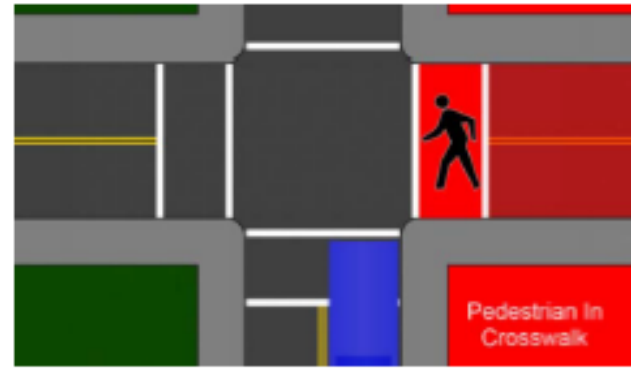

PCW Warning Display Screen

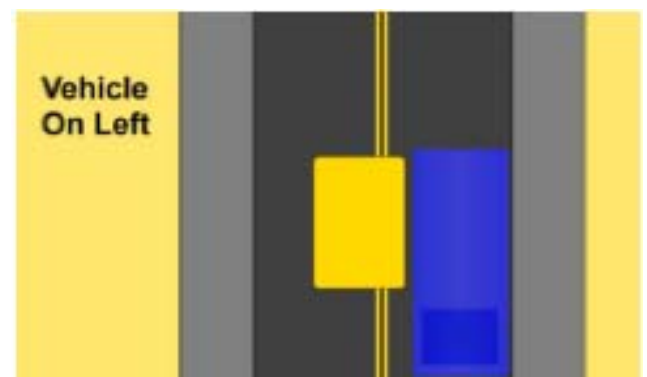

VTRW Inform Display Screen

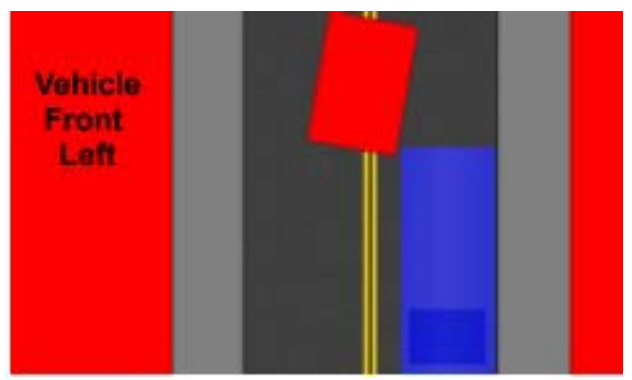

VTRW Warning Display Screen

Source: Battelle

Figure 3 User Interface Display Screens

The final report of the Transit Retrofit Project will soon be published by USDOT. CUTR was allowed to review an advance copy of the report. The executive summary noted eight major conclusions.

- The on-bus software was effective at providing alerts to transit drivers.

- The transit drivers expressed acceptance of the concept.

- The Pedestrian Crosswalk Warning (PCW) application experienced a high rate of false alerts due primarily to a combination of Global Positioning System (GPS) limitations and pedestrian detector limitations. 
- The Vehicle Turning Right Warning (VTRW) application experienced a high rate of false alerts due to GPS limitations.

- GPS locational inaccuracy was a root cause of VTRW target misclassifications and a defeating factor for PCW lane tracking. A more precise technology, such as Differential GPS, should be employed to achieve expected performance levels.

- The Doppler microwave-based crosswalk detectors are insufficient for the PCW application. ${ }^{6}$ They cannot adequately discern between pedestrians and slow moving vehicles in the crosswalks. A more discerning technology, such as high-speed imaging, should be employed to achieve expected performance levels.

- $\mathrm{DSRC}$ radio technology performed well - there were no problems traced to DSRC radio communications.

- The short-term system revisions yielded expected performance improvements.

There were no specific comments in the report regarding how well the Forward Collision Warning (FCW), Emergency Electronic Brake Lights (EEBL), and Curve Speed Warning (CSW) performed.

The developer for the transit safety retrofit is the Battelle Memorial Institute. ${ }^{7}$ The project manager at Battelle is Mr. Rob Zimmer, zimmerre@battelle.org. The project manager at the FTA is Steve Mortensen, Senior ITS Engineer, Office of Research Demonstration, and Innovation, steven.mortensen@dot.gov.

\section{Personal Rapid Transit}

The Advanced Transit Association (ATRA) defines Personal Rapid Transit (PRT) as having several characteristics. ${ }^{8}$ They include: direct origin-to-destination service with no need to transfer or stop at intermediate stations; small vehicles available for the exclusive use of an individual or small group traveling together by choice; service available on demand by the user rather than on fixed schedules; fully automated vehicles (no human drivers) which can be available for use 24 hours a day, 7 days a week; vehicles captive to a guideway that is reserved for their exclusive use; small (narrow and light) guideways are usually elevated but also can be at or near ground level or underground and; vehicles able to use all guideways and stations on a fully connected PRT network. PRT is sometimes referred to by the term "podcars". Essentially, PRT can be described as a system of driverless taxicabs that takes passengers to their destination along dedicated guideways without intermediate stops.

\footnotetext{
${ }^{6}$ The pedestrian detector used was the SmartWalk XP made by MS-SEDCO.

${ }^{7}$ http://www.its.dot.gov/factsheets/pdf/TransitSafetyRetrofit_V6_NoCropMarks.pdf

${ }^{8}$ www.prtconsulting.com
} 
Currently, the only operational PRT in the United States is in Morgantown, West Virginia on the campus of West Virginia University. It is a four-mile system that has been in operation since 1974. A picture of the Morgantown PRT is shown in Figure 4. The podcars have the ability to bypass stations. The campus PRT webpage states that it carries approximately 15,000 riders per day during the school year. Each car can accommodate 8 seated passengers and carry up to 20 comfortably. The most recent data on the Morgantown PRT from the National Transit Database (NTD) is shown in Table 1.

Table 1 Morgantown PRT Statistics

\begin{tabular}{|l|r|}
\hline Passenger trips & $2,337,261$ \\
\hline Operating expenses & $\$ 5,122,161$ \\
\hline Revenue miles & 829,038 \\
\hline Revenue hours & 204,408 \\
\hline & $\$ 6.18$ \\
\hline Cost per revenue mile & $\$ 25.06$ \\
\hline Cost per revenue hour & $\$ 2.19$ \\
\hline Cost per passenger trip & \\
\hline
\end{tabular}

Source: 2012 National Transit Database

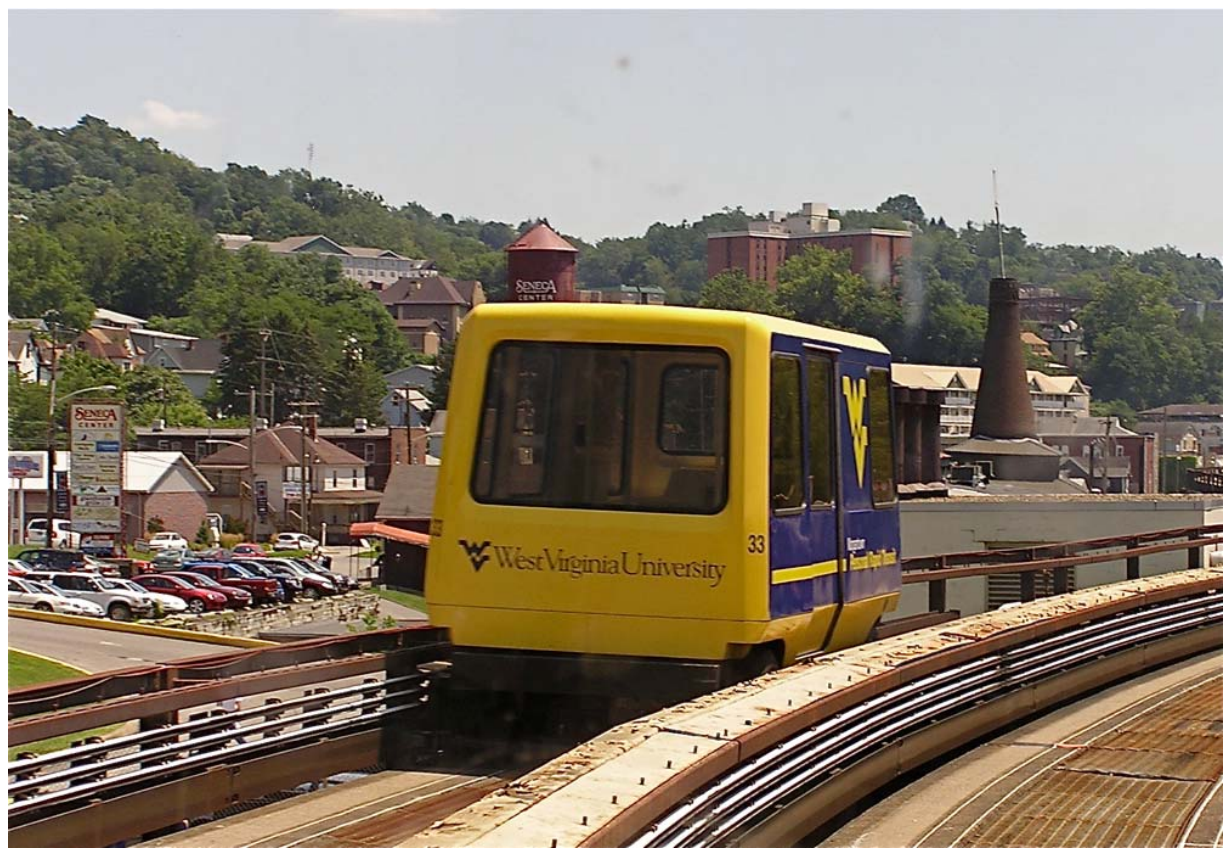

Source: Wikipedia

Figure 4 Morgantown PRT

Although the Morgantown PRT has been operating safely since 1975, its rocky start has soured further interest in PRT by the federal government ever since. As reported by Steve Raney and Stan Young in a 2004 Transportation Research Board paper, the Morgantown PRT began as demonstration project with an original cost estimate between $\$ 15$ and \$20 million. When it 
finally opened, the final costs had skyrocketed to $\$ 130$ million. ${ }^{9}$ Furthermore, on its opening day, Tricia Nixon, President Nixon's daughter, ended up being stranded in the middle of the track when the first vehicle jammed.

Outside the U.S., there are only three other examples of operational PRT worldwide. They are located in the city of Masdar in the United Arab Emirates, at Heathrow Airport in London, and at the Suncheon Bay coastal eco-park in South Korea. Pictures of these three PRTs are shown in Figure 5 through Figure 7.

The city of Masdar in the United Arab Emirates commenced operations of a PRT system in November 2010. The PRT was developed by the company 2 getthere. ${ }^{10}$ The original plan was for a driverless fleet of 3,000 free-moving, magnetically guided podcars. A news article from 2011 reported however that the city has since backed away from implementing the full system due to high costs. ${ }^{11}$ At present, the operational PRT in Masdar consists of 13 podcars that shuttle students along half mile stretch between a station and a post-graduate university. No information could be found on the capital or operating costs.

Since 2011, Heathrow Airport in London has operated a PRT system developed by the company ULTra. It operates in a one-way $3.8 \mathrm{~km}$ ( 2.4 mile) guideway between the T5 Business Car Park and Terminal 5 . The system consists of 21 podcars and has three stations. The ULTra website reports that it carries 800 passengers per day. ${ }^{12}$ According to a news article, the system cost $£ 30$ million (\$51 million). ${ }^{13}$ That equates to $\$ 21.25$ million per mile. The ULTra website states that a complete ULTra PRT system, including stations, guideway, vehicles, and control systems will cost between $\$ 7$ to $\$ 15$ million per kilometer, which equates to $\$ 11$ to $\$ 24$ million per mile.

In August 2013, trial operations began of a PRT system at the Suncheon Bay coastal eco-park in South Korea. This was a privately funded project. The PRT system was designed and built by Vectus, which is a subsidiary of the Korean steel manufacturer POSCO. The PRT operates on a $4.64 \mathrm{~km}$ ( 2.9 mile) track and has two stations. Station 1 is located at the entrance to the International Garden Expo, and Station 2 is located at the Suncheon Literature Museum. It will operate 40 podcars. ${ }^{14}$ The ridership forecast is 5,000 riders per day. ${ }^{15}$ No information could be found on the capital or operating costs.

\footnotetext{
${ }^{9}$ http://www.cities21.org/morgantown_TRB_111504.pdf

${ }^{10}$ http://www.2getthere.eu/?page id $=\overline{10}$

11 http://singularityhub.com/2011/03/01/masdar-city-abandons-public-transportation-system-of-the-future/

12 http://www.ultraglobalprt.com/wheres-it-used/heathrow-t5/

13 http://www.huffingtonpost.co.uk/2011/09/12/heathrow-driverless-pods-n $958262 . \mathrm{html}$

${ }_{14}$ Kojects, "PRT System to Open for Suncheon Bay Garden Expo", http://kojects.com/2013/02/13/prt-system-toopen-in-april-for-suncheon-bay-garden-expo/

15 “Personal Rapid Transit Evaluation" report prepared by PRT Consulting and TranSystems for the Greenville Economic Development Corporation, June 2014, http://www.greenvillecounty.org/gcpc/transportation_planning/pdf/gcedc_prt_evaluation final.pdf , p.36.
} 


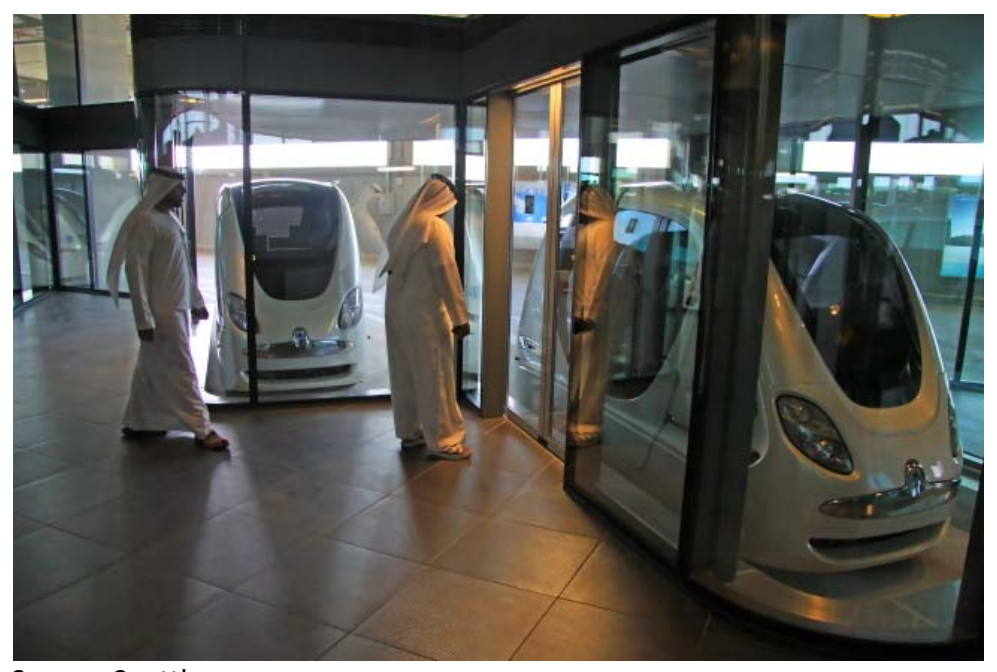

Source: 2getthere

Figure 5 City of Masdar (U.A.E.) PRT

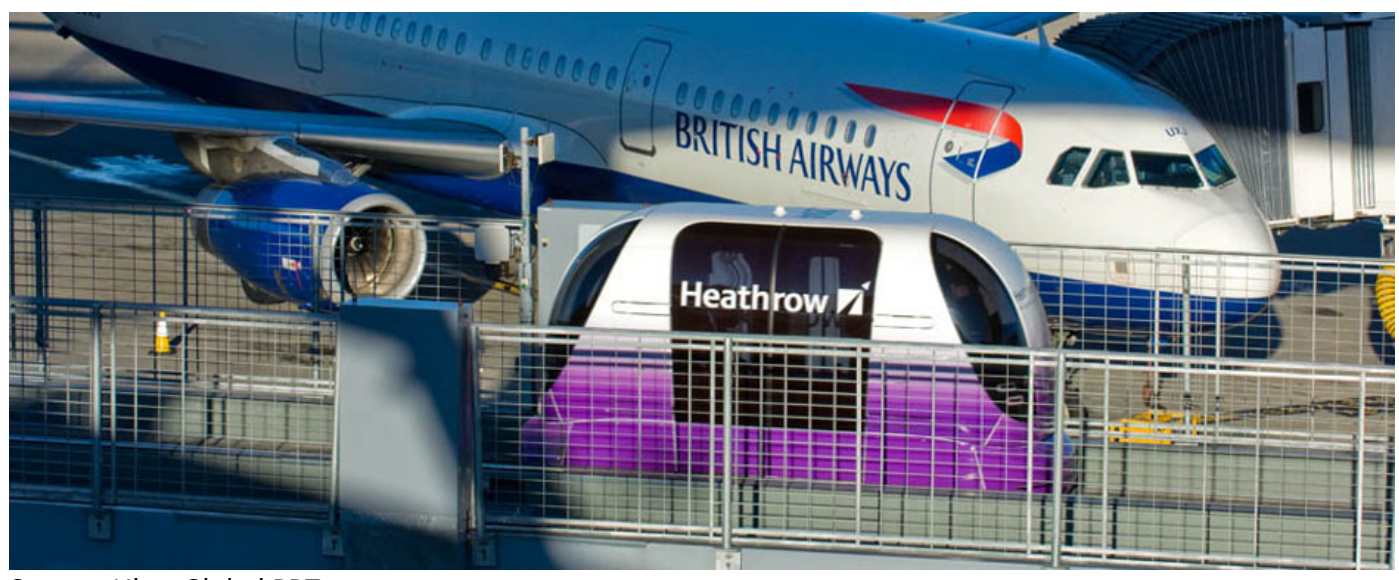

Source: Ultra Global PRT

Figure 6 London Heathrow Airport PRT

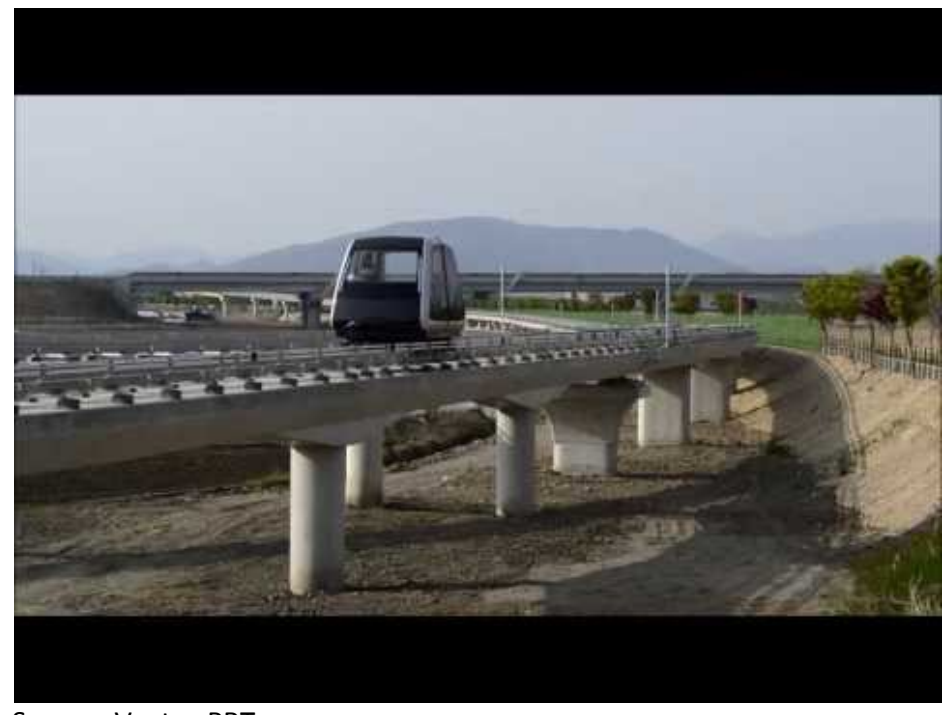

Source: Vectus PRT

Figure 7 Suncheon (South Korea) PRT 


\section{Conclusions}

The purpose of this report was to provide an overview of the state of automated vehicle (AV) technology in transit. Unfortunately, the options currently available are limited. It appears that for the moment any transit-related demonstration of AV technology would involve prototypes and require both significant engineering work and retrofitting of buses. Unlike the automotive industry which has invested a substantial amount of money into AV technology, there have not been similar AV developments in the transit industry. With the exception of Nova Bus/Volvo, none of the bus manufacturers contacted by CUTR have any immediate plans to add AV technology to their buses. The only two examples of AV technology in operational use by U.S. transit agencies are both prototypes developed by university engineers. The only transit-related AV project that CUTR could find involving a commercial manufacturer was a project sponsored the San Diego Association of Governments in collaboration with TRW Automotive. However, that project did not come to fruition.

The development of transit-related Connected Vehicle (CV) technology has also been very limited in scope. While the automotive side of USDOT's Connected Vehicle Safety Pilot Model Deployment involved collaboration with Ford, General Motors, Honda, Hyundai-Kia, MercedesBenz, Nissan, Toyota, and Volkswagen, no bus manufacturers were involved in the pilot program. Instead, the transit-related CV applications in the pilot program were prototypes developed by the Battelle Memorial Institute and retrofitted onto three University of Michigan buses.

Finally, Personal Rapid Transit (PRT) or "podcars" seems to be an idea whose time will never come. Although the Morgantown PRT has been operating safely since 1975, its rocky start soured further interest in PRT by the federal government. The City of Masdar in the United Arab Emirates originally had ambitious plans for a city-wide fleet of 3,000 PRT vehicles. However, even oil-rich Masdar has backed away from implementing a full PRT system due to high costs. 